\title{
Consent, confidentiality and the ethics of PAR in the context of prison research.
}

DOI 10.1108/S1042-3192(2012)0000012011

\author{
James Ward, BSc (Hons), PG Dip, ${ }^{1}$ \\ Di Bailey BSc (Hons), MSc, CQSW, ASW, Dip Inn Mental Health \\ From the School of Applied Social Sciences, Durham University and the School of Social \\ Sciences, Nottingham Trent University.
}

This article is $@$ Emerald Group Publishing and permission has been granted for this version to appear here (http://irep.ntu.ac.uk/R/-?func=dbin-jumpfull\&amp;object_id=216101\&amp;silo_library=GEN01). Emerald does not grant permission for this article to be further copied/distributed or hosted elsewhere without the express permission from Emerald Group Publishing Limited.

1 Address for correspondence: James Ward, 47 Finchale Avenue, Brasside, Durham, DH1 5SD 
A broad spectrum of research takes place in the prison environment, ranging from epidemiological studies of diseases to outcome studies of offending behaviour programmes. Researchers interested in prison populations reflect this heterogeneity and include Forensic Psychologists in Training, health and welfare commissioners, academics and staff based in independent organisations such as the Howard League for Penal Reform.

It may be unsurprising that prison research is popular as it captures issues relating to a discreet, confined and generally static population. Offenders in custody are costly to care for and have complex needs relating to criminogenic risk factors, mental health and social inequalities. Any research that aims to maximise improvement and efficiency of custodial care must achieve this within a climate of risk management and public safety. This raises complex ethical dilemmas that are compounded by the coercive custodial environment and research interests that often do not benefit the prisoners directly (Crighton, 2006). The varying and different needs of prisoners involved in the research (often labelled as vulnerable, Moser et al., 2004) and the toll taken upon chief investigators trying to manage the complexity of ethical considerations add to the complexity. As Towl (2004) highlights while such ethical considerations are not exclusive to prison based research, the custodial environment does often magnify these issues producing significant ethical constraints that are distinctive to the custodial setting.

This chapter seeks to discuss the ethical issues of conducting a study using a participatory action research (PAR) design in a prison setting. The authors draw upon their experiences of using the PAR methodology in a project that aimed to reduce incidences of self-harm whilst improving outcomes for women who continue to self-injure in custody. The project was funded as a Knowledge Transfer Partnership between offender health commissioners, a university and a women's prison in England.

Particular attention will be given to the key ethical dilemmas of involving the women offenders in this research. Given the nature of the PAR process the chapter will discuss issues relating to informed consent and emphasising and promoting choice in participation amongst disempowered groups such as prisoners. An exploration of the limits of confidentiality and maintaining anonymity in an environment which ordinarily does not prioritise such considerations above security and safer custody will also be provided.

\section{Why Participatory Action Research?}

PAR is a methodological process through which the researcher seeks to address or improve identified areas of need by way of action and intervention involving those who are a part of the research process (Dick, 2002; Reason \& Bradbury, 2001). This therefore distinguishes it from other epistemological methodologies which seek solely to generate knowledge through observation or effect causal change through experimental means. PAR is a cyclical process involving three distinct phases of planning, action, and critical reflection (Lewin, 1946). Figure 1 illustrates two cycles 
of the process as realised in the current project; each stage is numerically ordered 16. As Dick (ibid) describes the PAR cycle is flexible allowing the authors to respond to the needs of all the stakeholders throughout the project lifespan. This was considered vital in a custodial environment where the welfare needs of service users were tempered because of security constraints. Critically PAR seeks to involve all stakeholders relevant to the identified area for change in all stages of the cycle (Wadsworth, 1998) with potential for democratic and emancipatory outcomes (Whyte, 1991). This methodology was deemed particularly relevant in improving outcomes for women whose self-harming behaviour is likely to be linked with stigma, mediated through social rejection or as an attempt to control threats to selfidentity (Balsam et al 2005). For women in custody who experience additional stigma as a result of their offending behaviour and status as a prisoner (Allen, 1987) PAR offered a methodology that would foster engagement and take a needs led approach to the research and subsequent courses of action. One of the objectives of the project was therefore to involve women in prison in the process of change rather than change being imposed upon them as is often the case in secure environments. The authors aimed to achieve, for the first time in a prison environment, what Faulkner (2004) described as the "epitome of emancipatory research" by "facilitat[ing] the active participation and hence potentially the empowerment of those who are traditionally most disempowered by the research process" (p.27).

Figure 1 The PAR process and how this was realised through the project.

Such an ambition however is fraught with difficulty in an environment that is by its very nature disempowering and undemocratic. Prison restricts freedom and access to resources as a method of maintaining security and discipline as well as providing punishment for crimes. In the case of self-harm prison policy does not allow for a harm reduction approach focussing solely upon prevention. To an extent therefore prison can even be seen to attempt to control what a prisoner can do to their own body. Adopting an approach such as PAR in a custodial setting with the aim of empowering prisoners can raise implications for security; create suspicion as to its motives and possibly raise expectations beyond what is achievable. The methodology may also raise wider questions about the rights of offenders to be involved in the development of services; this however is beyond the scope of this chapter. Instead we shall look at three themes that are particularly relevant to PAR and the ethical process. Firstly we shall discuss preparation for PAR particularly paying attention to the involvement of people in prison, commonly labelled as vulnerable, around sensitive topics such as self-harm. Secondly the action-research process itself will be examined in the light of specific requirements imposed by secure conditions. Finally the process of effecting change through PAR will be considered.

\section{Ethical Clearance and Planning PAR}


Obtaining ethical approval for prison based research can be difficult and time consuming and levels of bureaucracy can prove to be insurmountable resulting in cancellation of studies before they have begun (see Gill, 2009). Given the multidisciplinary nature of prison it was inevitable that research will involve multiple stakeholders. In all, our project required ethical approval from five organisations with differing agendas:

- The National Health Service Research Ethics Committee (NHS, REC)

- The Ministry of Justice

- The Primary Care Trust (PCT)

- The University

- The Prison.

Given the levels of bureaucracy involved a pertinent question would be whether these measures are essential in order to protect research participants and would be Cl's and whether the emphasis upon the protection of participants results in missed opportunities due to aversion to risk.

In the case of the current study a lot of emphasis was placed upon procedures to follow should a participant become distressed or self-harm as a result of participation. This was considered to be particularly relevant given that interviews were likely to touch upon distressing events in the woman's life. The reality of the research however was that distress during the process was minimal and, to our knowledge there were no incidents of self-harm as a result of participation. Instead many women and staff reported that their experience of participation was beneficial for them personally and that they were optimistic about the impact it could have in facilitating change.

We asked one woman to write about her experiences of being involved throughout the three years of the project. She was keen to contextualise the experience and her use of self-harm with her life experiences. This is what she wrote:

My name is Janet, I am a prisoner. I have an Indeterminate Sentence for Public Protection.

I self-harm and have done since a very young age. I went through a bad time when I was growing up and to me it was bad, but compared to some people's lives it wasn't. I lived with my grandparents from being born I called my Granddad Dad and I couldn't do without them. I was 9 years old when they both suddenly got ill and then died within 6 weeks of each other. I was devastated and my life and world was destroyed within a couple of weeks. On the day of my Nan's funeral I went to live a new life with my Mum, step dad and 4 siblings who I hardly knew, they were strangers to me. I felt uneasy around my step dad and felt him leering over me. I was never comfortable in the company of the strangers that had become my new family. I was always fighting with my brothers and sister, there were also physical fights with my step father neither of us was hurt but it took its toll. One day when I 
was 11 years old I released the sharp, silver blade from a pencil sharpener and cut a ladder of perfectly, neat rungs down the inside of my left arm. The surprising thing was that it didn't even hurt and I didn't feel that I was doing anything wrong. I knew thought that I had to hide my secret escape-ladder. For the first time since my parents died I felt an immense relief from my tormented world of trauma, upset and grief. I felt alive again. I felt as though I could speak out loud, scream without anyone hearing me, because all that time, I was screaming inside and was about to explode.

A number of years down the line in prison, I met [the researcher] who was working on research at the prison. He approached me to see if I wanted to take part in some work on self-harm and put a staff training package together.

I had more self control by then and had been diagnosed with Bipolar Disorder and receiving help for that. Still I went away to give myself some time to think about the potential consequences of getting involved in something that was so close to me and was actually a part of me. I wasn't sure if I was willing to let strangers delve into my past and to know so much the where's and why's of my life. From discussing it, it turned out that it wasn't invasive at all, so I thought l'd give it a shot.

Taking part helped me in many ways including channel some pent up anger. We put together a small group of women who use or who had used self-harm to create a training package. People use it as a way of getting what they want to say across, but cant' express themselves in any other way. We created the training to particularly help staff, but also women in prison, to understand why some people self-harm and to explain what degrees someone is willing to go to for a release from the reality of the world they live in. I also worked with James to put together leaflets and posters with some of my art work and pieces of writing to show and describe what self-harm is all about, what it is and what it isn't.

I feel really proud of what I and others produced because. It gave me a feeling of belonging and I didn't feel that I was the only one who had ever harmed myself because that's how self harm made me feel, it like an outsider, alone, weak and unable to cope with life. I now feel as though I have got my point across and explained my part and why I do what I do without embarrassment. Taking part also gave me an insight into things I didn't quite understand about myself. I hope that it will help others to understand and maybe have a bit more empathy, not "sympathy" for those who self-harm in the future. I think we also showed that there are many reasons why people use self-harm and many types of ways and that people harm themselves. I am so pleased that I was approached, but mostly pleased that I was given this chance, because now my problems are shared and now halved.

Thank you for taking your time to read this little snippet of my life that's so similar to that of many, many other people:

I am Janet and I am a self harmer, but I am also still human. 
Janet's decision to become involved was, for her, a weighing of the potential consequences of what could have proven to be an intrusive process. Her experience however reflects a growing body of literature that testifies to the positives of participation provided it is well thought out and ethically sound. This suggests that ethics committees in their concern to protect research participant may not be up-todate with emerging findings around the potential benefits of asking about issues such as abuse (Edwards, Dube, Felitti \& Anda, 2007; Read, 2007) or the potential therapeutic benefits for people of involvement in such studies (Rossiter \& VerdunJones, 2011) if done with sensitivity. Committees may also fail to differentiate between distress and harm adequately, either not considering the possible positive aspects of becoming upset or attempting to shield service users from upset to such a degree as to make them feel patronised (Faulkner, 2004). Choice in participation will itself undoubtedly be empowering for those who are disempowered even if the research process itself does not produce change. For Janet the concern was less about exacerbating self-harm than the intrusion of privacy that taking part might entail. For those exposed to the daily stresses of a prison environment the experience or definition of harm may be different from others in different environments.

PAR's emphasis on 'participants' not being passive subjects in research but equal collaborators can prove vital in the preparation for research. Involving the women in decisions on how they want to be involved, on what terms they want to contribute and the management of risk to themselves offered, in reality, more protection ${ }^{2}$ than any amount of preparation for the REC could. This empowerment and discussion about risk led to women choosing to be interviewed with partners and friends or around contact with mental health workers all of whom could offer support should they become distressed. This isn't to say that the REC has no value and its requirements invalid. Instead in the case of research involving sensitive topics such as self-harm it emphasises the importance of involving potential participants in an active way from the very outset, including in safety planning. It is worth noting that current guidelines allow for the active involvement of service users and/or potential research participants in planning process before ethical approval (Involve, 2009).

PAR also provided the means to maintain contact with participants through either chance or planned meetings around the prison. After the research process this was usually to work on service development but also allowed us to check on the participant's welfare and keep them informed of the progress of the project. In the case of the women who had participated this also gave them the opportunity to ask for resources such as puzzles and distraction activities that they found useful in managing self-harm and that we could provide. As such there was plenty of opportunity to continue to meet with the women involved after data collection which allowed us to monitor for any adverse consequences of participation.

\footnotetext{
${ }^{2}$ Arguably those who chose to engage with our research didn't want or need protecting but required all the information and choices available to them.
} 
When conducting research around sensitive topics the safety, both physically and emotionally, of the Chief Investigator $(\mathrm{Cl})$ is also of concern. Whether the researcher will be 'lone working' or accompanied by a member of prison staff has implications for the research findings and security considerations. Research accompanied by prison staff may mean the $\mathrm{Cl}$ can bypass statutory prison service training such as security awareness and personal protection and may be a safeguard for the $\mathrm{Cl}$ (and in some cases the participants). However having a member of prison staff present is likely to impact upon how the person responds or add an element of coercion that a $\mathrm{Cl}$ independent of the prison service may not. Gaining unaccompanied access to the prison may be desirable to help potential participants feel more at ease during the research process and will provide different data than if prison staff are present. In these cases considerations around personal safety and understanding prison service policy in the event of certain disclosures needs to be attended to (see below). In a similar way to Weiskopf's (2005) description of the prison nurse's needs to balance care and security so too must the $\mathrm{Cl}$ balance ethical considerations with security requirements.

In addition to physical safety the risk of vicarious (Dunkley and Whelan, 2006) or secondary (Motta, 2008) trauma is a real ethical concern in prison research. Vicarious trauma is often associated with therapists or mental health workers who are exposed to narratives of traumatic events (Sabin-Farrell \& Turpin, 2003) and particularly associated with empathic engagement (Pearlman \& Maclan, 1995). This can result in those listening to accounts of traumatic events experiencing similar feelings of distress, fear and other symptoms of post traumatic stress as those recounting the experience. Figley (1995a) described such effects upon the listener as the "cost of caring" (p.1). Such an impact may not be limited to those delivering therapies and are equally a consideration for researchers, particularly if the methodology involves life history accounts or is likely to touch upon topics such as trauma, abuse, self-injury and suicide. Even when the focus of research is not upon such emotive areas working with people with complex psycho-social needs, whilst also being able to identify when these needs are appropriate or inappropriate to address, requires detailed planning. As such the appropriate and timely use of supervision, occupational health resources and the Cl's ability to monitor and protect their own wellbeing also need to be considered in the planning stages of the research. This all assumes however that the research process is a negative experience and plans for worst case scenarios. If the experience is positive for the participants however it can be equally positive for the $\mathrm{Cl}$ and bring the benefits that any collaborative and productive working relationship can produce. This was our experience and there were no adverse consequences for the $\mathrm{Cl}$ but that is not to say that vicarious trauma does not need consideration.

\section{The Action Stage - Producing Change}

The need for balance in the preparation for PAR in prisons has been highlighted a number of times already. This is equally, if not more, true in the action stages in which participants will become actively involved in the process of effecting change. 
Specifically a balance needs to be struck between three competing, although not mutually exclusive, needs. These are

1. The needs of those who become involved in the PAR process. In our project this was both staff and women in prison. It was the responsibility of the project team to properly represent the opinions and needs of those who gave their time to be involved.

2. The needs of the prison to maintain security, fulfil its duty of care to prisoners and staff and adhere to national policy and legislation.

3. The needs of the research. This in itself is a combination of ensuring rigour and objectivity in its methods, being appealing in order to recruit and keep participants engaged and ensure that through adhering to regulations it can continue to have a presence in the prison.

We shall consider these three needs in relation to two crucial aspects of the Action stage of PAR, the recruitment of participants and the effecting change in working practices.

\section{Recruitment to Research}

Prisons provide a condensation of needs and issues that are present in the wider community. Those who are imprisoned are more likely to experience mental health difficulties, misuse or be dependent upon substances, have greater needs relating to literacy and numeracy, have experienced traumatic events such as violence or sexual violence in their past and are more likely to have been unemployed and/or homeless prior to imprisonment (see Stewart, 2008 for a thorough needs analysis of recently sentenced offenders). These complex and multifaceted needs are often described as vulnerabilities for the potential research participant. Whilst the label of 'vulnerable' has been criticised for being further stigmatising and unhelpful (Corston, 2007) such factors require consideration in the research process even when they are not the focus of enquiry.

Considering the needs of the individual is likely to have the largest impact upon the recruitment to research. The inclusion criteria of our study was for women to have a recorded incident of self-harm whilst in prison as identified through their prison records (all staff who worked directly with prisoners were eligible to participate). This was limited however by a number of factors. Whilst the issue of capacity and the person's ability to provide informed consent was relevant, the exclusion of potential participants due to the prison's operational requirements impacted more upon the recruitment to the project. Although the original intention of our study was to approach all the women in the prison who met our criteria compromises had to be made. Agreements were reached with the prison's security department regarding not including women who were of media interest due to concerns about data security and especially recorded interviews. In other cases clinical teams requested that 
women be 'exempt' from the study because of a clinical judgement that their involvement would exacerbate their self-harm which was already potentially life threatening. The reality therefore was that some women who were eligible to participate, and would have undoubtedly brought a unique and valuable aspect to the research, were not even approached. This creates limits on the research itself and highlights the necessity to sometimes remove power from those in prison to make choices about whether to be involved in initiatives or not. Again however this assumes that the process will be negative and that women won't be able to manage any distress after the event. Whilst acknowledging that this may be the case for some women our experience suggests otherwise for the vast majority who chose to become involved. It is unfortunate that perhaps the women whose self-harm was at its worst and who may have benefited from involvement the most were not given the opportunity to take part. To approach these women however would have required the $\mathrm{Cl}$ to dismiss the concerns of the responsible clinicians potentially jeopardising the needs of the prison and the project. Ideally discussions around the nature of the risk posed by involvement could have been held as a part of a care management process involving the women and staff to find an agreeable compromise.

\section{Informed Consent in a Coercive Environment}

Whilst for some in a prison setting the ability to choose to become involved is removed for others the issue of coercion to participate is of equal concern. Coercion is institutionalised within prisons and in many ways contributes to the maintenance of discipline and order within the establishments. This can be seen in the use of adjudications and sanctions against sentenced prisoners refusing to work and the progression of prisoners being dependent upon them conforming to their sentence plan ${ }^{3}$. Whilst Day, Tucker \& Howells, (2004) suggest that coercion is not inherently unethical, citing having to pay taxes as an example, we would argue that in relation to research coercion is the antithesis of truly informed consent.

Moser et al., (2004) highlights that with such a marginalised population as those in prison coercion can be very broadly defined to the extent of

"The fact that participation may enable the inmate to leave his or her cell more frequently and interact with people from outside the facility is a form of potential coercion" (p.2).

Whilst opportunities such as talking to someone new are an unavoidably inherent aspect of prison research, care has to be taken that coercion is not implied or unintentionally a feature of the research. The longer-term nature of PAR certainly offers more opportunities for interaction and possibly time out of cells. If this is the

\footnotetext{
${ }^{3}$ A Sentence Plan is a set of targets the prisoner is expected to complete in order to reduce their risk of re-offending. Often these will include educational, therapeutic and offending behaviour interventions. For prisoners on life sentence and indeterminate sentences their progression through the prison system, and their eventual release is dependent upon them completing their sentence plan. That therapeutic and psychological based interventions are often included is much discussed and whether this constitutes and anti-therapeutic level of coercion is debated (see Day, Tucker \& Howells, 2004)
} 
case however PAR approaches could be argued to provide meaningful activities that should be integral to the prison regime anyway. People in prison may become unaccustomed to being able to refuse to take part in activities due to staff-prisoner relationships often being an "instrument of power" (Liebling, 2001). Prisoners may also be wary of the consequences of refusing to participate (for example fearing sanctions for declining) or may want to appear cooperative in the expectation of better treatment or increased privileges (Moser et al., 2004).

Again PAR and the nature of the working relationships between all those involved in the research can go some way to addressing issues of coercion. The traditional roles of researcher and participant have implications for the power relationship casting the Researcher as an active agent whilst the Participant as passive and controlled. This has lead to a number of criticisms about participant-researcher relationships, most notably by feminist researchers who not only highlight issue of control but also of mastery or expertise being the sole preserve of the researcher (Stanley and Wise, 1983). Such power relationships can be magnified through the prison lens where the researcher may be a member of staff whilst a prisoner's position is disempowered by her very position. As such refusing to become involved or choosing to be no longer involved in research may be a more difficult decision for those in prison. In our study through taking time to explain the options and choices around engagement this did not appear to be a problem. As Janet testifies she took the time to consider her decision and this was encouraged of all women who we approached to take part.

The issue of payment is also an ethical dilemma that needs to be addressed. There are a number of guidelines, especially for those involved in the service user movements, suggesting payment should be offered to people who give their time to participate in research (Faulkner, 2004, INVOLVE, 2006). This practice however is not supported by the Prison Service (Prison Service Instruction 41/2010) due to concern about the use of the money for illicit purposes (Sneddon, 2005). The use of payment may also introduce a further element of coercion. Most people in prison have the opportunity to earn wages through work, however these are small sums of money that can be used for buying additional supplies such as toiletries and confectionary. During discussions about our research there was a division of opinion amongst the team about this issue. Whilst some thought there was an ethical obligation to compensate those who gave their time, others had concerns that payment would unfairly disadvantage those who were not eligible to participate. In our experience the issue of payment never arose, even for women who have contributed for the three full years through the service development and evaluation. The exceptionally high rates of return for questionnaires (89\%) suggests that an opportunity to be involved and have a stake in change was sufficient.

It is apparent that when used properly PAR provides a strong framework for the development of collaborative working relationships with participants. This is not only based upon the voluntary nature of the relationship but also a basis that acknowledges the experiential expertise that participants can bring to the research 
(Beresford, 2000). This approach of taking time to discuss the options for involvement with potential participants differs from a lot of research conducted in prisons where questionnaires are put under prisoner's cell doors during times they are confined to their room with the expectation they will be completed and returned with minimal contact from the $\mathrm{Cl}$.

The nature of the working relationship in a prison environment can never be truly equal however. This is perhaps best exemplified by the Cl's inability to offer total confidentiality to participants. Prison policy requires all incidents or increased risk of self-harm be reported and action taken to place the person under the care of the Assessment Care in Custody and Teamwork (ACCT) process. This is clearly in conflict with the ethical protection of total confidentiality and anonymity usually offered to the participant during research. It also potentially impacts upon the development of relationships within the working collaboration requiring clear 'rules' to be set out as to what can be held in confidence and what will have to be passed on. Again balance is required to be struck between participant confidentiality whilst adhering to the prison service's duty of care and security procedures to allow us continued access to the jail.

Similarly the $\mathrm{Cl}$ may be required to structure the expectations of what is achievable in order not to instil false hope. This was perhaps most demonstrable in our project by the $\mathrm{Cl}$ not taking forward suggestions for additional resources (one example being a Rubik's Cube) to the prison management based upon his knowledge that they had been previously refused on security grounds. Such examples demonstrate an obvious power difference with the $\mathrm{Cl}$ influencing what suggestions were and were not progressed albeit for pragmatic reasons. We tried to manage this by being honest about what was achievable when suggestions were made but also pushing boundaries to implement initiatives that had not previously been tried and challenging senior managers about what was achievable when.

\section{Effecting Change in Prisons}

PAR is of course not just about collaborative work with those who are most marginalised (e.g. prisoners) but is equally applied to all involved in the process. Prison staff too can also be marginalised and deserve the same protections from power relationships through research. Liebling (2001) describes the "intellectual hegemony", (p.476) of prison research focussing upon prisoners to the detriment of studying the way power is used by those managing the prison system. Her argument that sympathy should not always be reserved for the subordinate prisoners but that managers and governors will also be in someway subordinate and also vulnerable to coercion make them equally deserving of a sympathetic approach. It is perhaps Liebling's affinity with value neutrality, or the suspension of personal beliefs about the way things should be, that leads her to conclude that "Whose side are we on? The side of prudent, perhaps reserved engagement." (ibid, p. 483). Liebling certainly isn't the only researcher to compromise (see Martel, 2004) and it can be argued that sensitivity and respect for prison governance is essential in order to inform productive working relationships. Such reserved engagement is perhaps 
unlikely to produce substantial or comprehensive change that may be required. Such a conservative approach is, at best, more likely to result in evolution of existing processes rather than true empowerment of those involved or introduction of new methods of work (akin to consultative service user engagement on the Hickey \& Kipping's (1998) Participation Continuum as opposed to User Controlled research). The $\mathrm{Cl}$ is then left with the ethical dilemma of how to negotiate, implement and evaluate change in an institution which does not embrace change readily but without the use of coercion towards prison staff either. This has requires translating the work of the research process with prisoners in identifying problems and developing solutions in to business cases. The $\mathrm{Cl}$ effectively becomes a go between representing the prisoners to the prison senior management and vice versa. Ideally prisoner councils similar to those set up by the organisation User Voice could be arranged to allow prisoners to directly represent themselves and make suggestions for change. This would however necessitate the prison's senior management to allow themselves to be openly led, to some degree, by the ideas of prisoners. It was deemed in our case that a more neutral representative (the $\mathrm{Cl}$ ) would be more effective.

Over the three year course of our research there were significant changes which impacted upon implementation of change in the jail. These included internal restructuring of the prison's senior management team whilst externally the recession resulted in tight budgetary constraints which contributed to prison staff job loses. Given all this, understandably, driving change through PAR was not a priority for the prison. Again this required the project team to strike a balance. On the one hand we had a responsibility to represent the women and staff who had given their time to the project and attempt to improve care based upon their experiences. A failure to assert the work done would be to let down participants and lose the opportunity to effect change. To be unrealistic or too demanding of senior management, however, would be to lose their respect and build their resistance to change. Liebling (ibid) observes that it is of course possible to be sympathetic to more than one side and this is reflected in our approach that is probably best described as 'picking our

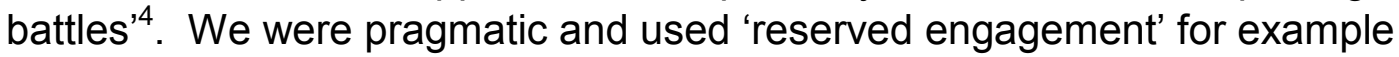
conceding ideas about involving more multidisciplinary staff in ACCT case management at a time when there were concerns about job roles and potential losses. At other times we felt a duty to represent participants and this meant more assertively (or doggedly) pursuing initiatives with the support of external stakeholders such as the Offender Health Commissioners. These 'no compromise' issues included prisoners co-delivering staff training and proposals to allow, in some cases, women to dress their own self-inflicted wounds. The battles we picked to pursue were those that were held to be the most important by staff and the women in the prison and that had been previously untested in the prison environment. In this

\footnotetext{
${ }^{4}$ To describe the discussions we had about certain initiatives as battles is to overstate the confrontation that we encountered and the phrase is used as an illustrative metaphor. The reality in relation to initiatives such as the staff training was more a case of reservation and concern, given that no precedent had existed in the prison. The suggestion of providing women with wound dressings was met with an overwhelming aversion to risk and an understandable concern to protect the women and the prison staff but highlighted the idiosyncrasies of the prison environment.
} 
respect we feel we have gone some way to empowering women and staff in the prison and that this has produced positive change, even in the light of compromise.

It is worth ending with the reflections of another woman 'Claire' who was actively involved in the development and delivery of a staff training package named At Arm's Length. This was successfully delivered to a range of multi-disciplinary staff around the prison as one of the 'no-compromise' issues after its was identified as a need by both staff and women in prison.

I didn't know anything about the 'At Arm's Length' project until I found out that my name had been put forward as someone who had the ability to deliver PowerPoint presentations. Once I was introduced [the researcher], I had a look over the material and decided that it was something I would like to be involved with. I did have reservations about my ability to deliver presentations to staff, not because I didn't think I was capable, I just doubted myself being able to put aside the irrational assumptions I was thinking in regards to staff opinion of me. But I decided to stick it out regardless. I felt that, as an prisoner, I had somewhat of a responsibility towards the girls who had worked with [the researcher] to make the project as they had put so much work in to it and in a way I felt like I was representing them. There were times when, mostly due to nerves, I didn't want to turn up but I did and I am glad not that I was as determined as I have gained so much confidence from it. My selfesteem and confidence have grown since getting involved with the 'Arm's Length' and I have greater understanding of self-harm. The most important this to me though is that I feel like the presentations are making a difference.

The response from staff has been a lot different than what I expected it to be. When we first started to roll out the presentations I thought that most staff would be sitting there thinking it was wrong for a prisoner to be telling them about anything, let alone self-harm which they deal with first hand on a daily basis. I assumed they would be looking at me with the opinion I had no right to tell them nothing as I was a prisoner. How wrong I was! The staff listen to what I have to say and it appears they appreciate the insight in to self-harm they get being as they get it from a prisoner's point of view. This is also reflected in the questions I get asked after almost each presentation and the comments that are written on the feedback forms. In my opinion I feel that the staff are different towards me as it seems they now feel they can approach me and me things without them worrying whether or not they are going to offend me.

I think that the awareness sessions have made a big difference and have given the staff a better understanding of self-harm in general. I believe the officers now feel that what they are doing is right which makes making them more confident in dealing with and helping self-harmers. Most importantly I believe it has gone a long way in addressing the prisoner-officer divide and as a prisoner it has been overwhelming the support and the positivity shown towards me. The staff's eagerness to engage 
and learn more, not just about self-harm but other subjects such as drugs, domestic violence etc. The staff are also utilising the packs ${ }^{5}$ and I have seen them using them with confidence. The activity boxes ${ }^{6}$, in my opinion, in the past have been viewed as nothing more than a waste of time, whereas the packs are being used as a legitimate tool that can help not only the women help themselves, but also help the staff help the women. I don't think that there is a prison in this country that wouldn't benefit from the same kind of awareness programmes.

\section{Conclusions}

The PAR process offers a number of opportunities to address the issues that a difficult working environment, such as a prison, raise for conducting ethically rigorous research. The approach offers a framework for engaging with disenfranchised and socially excluded populations by offering them a stake in effecting change that will hopefully prove to be positive. PAR also offers a method for developing and implementing effective systems of checks, balances and protections for those who choose to become involved.

Much of the research that is conducted in prisons can be considered to be applied however due to lack of generalisability, small sample sizes or resource constraints the application of findings is often found to be lacking (Hashmand \&O'Byrne, 1996, Crighton 2006). PAR however does not attempt to generalize its findings but instead solve specific, local problems through engagement with those with experiential expertise. To date this has been an under utilised approach in prison based research and whilst the initiatives that have emerged from the current study may not be generaliseable to other prisons however we suggest that the methodology is.

Whilst the focus of this chapter has been upon the use of a PAR methodology many of the issues raised will be equally applicable to other forms of prison research. Our experience leads us to offer some general do's and don'ts of conducting ethically sensitive research in prison.

\footnotetext{
5 The 'packs' are care planning action packs designed with the aim of empowering women to develop their own care plans and consider what actions they can take, and what they can ask of others, to help maintain mental wellbeing.

${ }^{6}$ Activity boxes contain activities for distraction such as puzzles, colouring sheets etc.
} 
Cobsent \& confidentiality in prison research

1. Be aware of the limitations of confidentiality and be clear and transparent about these with potential participants.

2. Be prepared for the fact that participants may become distressed, but don't let this stop you asking relevant questions. Knowing how to deescalate situations, review coping strategies and signpost to support appropriately is essential when working with people with complex psycho-social needs. However don't forget that the research process could also be beneficial for the individual if done with care.

3. Make necessary arrangements to maximise the person's ability to give properly informed consent. This involves both fully understanding the risks of participation as well as being able to choose which aspects of the research they can contribute to. Be prepared to make use of alternative methods of communication such as pictograms and translation services and be prepared to provide additional support where required.

4. Make use of supervision and occupational health resources and take responsibility for your own mental wellbeing.

5. Do be flexible and tenacious. The prison environment can often be unpredictable resulting in cancelled appointments, reduced regimes and research coming bottom of the list of priorities. Don't give up!

Don't:

1. Make promises that can't be kept. Ultimately the position of 'researcher' in the prison environment is also a disempowered one. Promising to effect changes that can't be realised is likely to increase cynicism towards research and reduce participation in the future.

2. Exceed the remit of conducting ethical and sympathetic research. De-briefs and empathic listening are important however it is not the Cls job to counsel those who give their time to research. Ensure participants are signposted to appropriate sources of support.

Ackn

owle

dge

ment

s:

We

would

also

ackno

wledg

e the

work

and

assist

ance

of the

wome

$\mathrm{n}$ and

staff

who

gave

their

time

and

experi

ence

during

the

course

of this

resear

ch

project

. Their

enthusiasm to contribute to change was very much appreciated. 
Consent \& confidentiality in prison research

Beresford, P. (2000) Service users' knowledge and social work theory: Conflict or collaboration? British Journal of Social Work. 30 489-503.

Corston, J. (2007) The Corston Report. Ministry of Justice. London, HMSO

Crighton, D.A. (2006) Methodological issues in psychological research in prisons. In G.J. Towl (Ed.) Psychological Research in Prisons. Oxford: Blackwell Publishing.

Damelio, R. (1996) The Basics of Process Mapping. New York: Productivity Press.

Day A., Tucker K., Howells K., (2004) Coerced offender rehabilitation - A defensible practice? Psychology Crime \& Law 10(3) SI, 259-269

Dick, B. (2002) Action research: action and research [On line]. Retrieved from: http://www.scu.edu.au/schools/gcm/ar/arp/aandr.html Last accessed 18th July 2011.

Dunkley, J., \& Whelan, T.A. (2006) Vicarious traumatisation: current status and future directions. British Journal of Guidance and Counselling, 34(1), 107-116.

Edwards, V.J., Dube, S.R., Felitti, V.J., \& Anda, R.F. (2007) Its OK to ask about past abuse. American Psychologist, May-June, 327-328.

Faulkner, A. (2004) The ethics of survivor research Guidelines for the ethical conduct of research carried out by mental health service users and survivors. Bristol: Policy Press.

Figley, C.R. (1995a) Compassion fatigue as secondary traumatic stress disorder: an overview. In C.R. Figley (ed) Compassion fatigue: coping with secondary traumatic stress disorder in those who treat the traumatized ( pp. 1-20). New York:

Brunner/Mazel

Foster, J., Tyrell, K., Cropper, V., \& Hunt, N. (2005). Welcome to the Team...Service Users in Staff Recruitment. Drink and Drugs News. 21.

Gill, J. (2009) Prison research project is throttled by red tape. Times Higher Education. Retrieved from http://www.timeshighereducation.co.uk/story.asp?sectioncode=26\&storycode $=40543$ 4 last accessed 25th October 2010

Hickey, G., \& Kipping, C. (1998) Exploring the concept of user involvement in mental health through a participation continuum. Journal of Clinical Nursing, 7(1), 83-88.

INVOLVE / DH (2006) A guide to reimbursing and paying members of the public who are actively involved in research: For researchers and research commissioners (who may also be people who use services). Eastleigh: INVOLVE Support Unit. Retrieved from: http://www.invo.org.uk/pdfs/payment guidefinal240806.pdf 
Consent \& confidentiality in prison research

Involve (2009) Patient and public involvement in research and research ethics committee review. Retrieved from:

http://www.invo.org.uk/pdfs/INVOLVE NRESfinalStatement310309.pdf

Last accessed 20th July 2011.

Lewin, K. (1946). Action Research and Minority problems. Journal of Social Issues, 2(4), 34-46.

Liebling, A. (2001). Whose side are we on? Theory, practice and allegiances in prisons research. British Journal of Criminology 41(3), 472-484.

Martel, J. (2004) Policing criminological knowledge: The Hazards of qualitative research on women in prison. Theoretical Criminology 8(2) 157-189.

Mental Capacity Act (2005) Code of Practice (2007) London: TSO.

Moser, D.J., Arndt, S., Kanz, J.E., Benjamin, M.L., Bayless, J.D., Reese, R.L., Paulsen, J.S. \& Flaum, M.A. (2004) Coercion and informed consent in research involving prisoners. Comprehensive Psychiatry 45(1) 1-9.

Motta, R.W. (2008) Secondary trauma. International Journal of Emergency Mental Health, 10(4), 291-298.

Pearlman, L.A., \& Maclan, P.S. (1995) Vicarious traumatization: An empirical study of the effects of trauma work on trauma therapists. Professional Psychology: Research and Practice, 26(6) 558-565.

Prison Service Instruction 41/2010. Retrieved from http://psi.hmprisonservice.gov.uk/psi 201041 research applications.doc last accessed 8th April 2011

Read, J. (2007) To ask or not to ask about abuse. New Zealand research. American Psychologist, May-June, 327-328.

Reason, P. \& Bradbury, H. (Eds.) (2001) Handbook of Action Research: Participative Inquiry and Practice, Sage: Thousand Oaks, California.

Rossiter, K., \& Verdun-Jones, S. (2011) Evidence-based ethical decision-making in research: Considerations from trauma-focussed research with women receiving forensic mental health services. Paper presented at the International Association of Forensic Mental Health.

Royal College of Nursing (2005) Informed Consent in Health and Social Care Research: RCN Guidance of Nurses. London: RCN. 
Sabin-Farrell, R., \& Tuprin, G. (2003) Vicarious traumatizaion: implications for the mental health workers? Clinical Psychology Review, 23, 449-480.

Sane (2008) Understanding Self-Harm. Retrieved from http://www.sane.org.uk/Research/SelfHarmIntro Last accessed 21st July 2011

Seddon, T. (2005) Paying drug users to take part in research: Justice, human rights and business perspectives on the use of incentive payments. Addiction Research and Theory, 13 (2) 101-109.

Sieber, J.E. (1994) The ethics and politics of sensitive research. In C.M. Renzetti \& R.M. Lee (Eds.) Researching Sensitive Topics. London: Sage.

Stanley, L. \& Wise, S. (1983) Breaking Out: Feminist Consciousness and Feminist Research. London: RKP

Stewart D (2008) The problems and needs of newly sentenced prisoners: Results from a national survey. Ministry of Justice Research. 16/08.

Towl, G.J. (2004a) Applied psychological services in HM Prison Service and the National Probation Service. In A.P.C Needs \& G.J. Towl (Eds.) Applying Psychology to Forensic Practice. Oxford: Blackwell Publishing.

Van Staden, G.W. \& Kruger, C. (2003). Incapacity to give informed consent owing to a mental disorder. Journal Medical Ethics, 29, 41-43.

Figure 2 The PAR process and how this was realised through the project. 


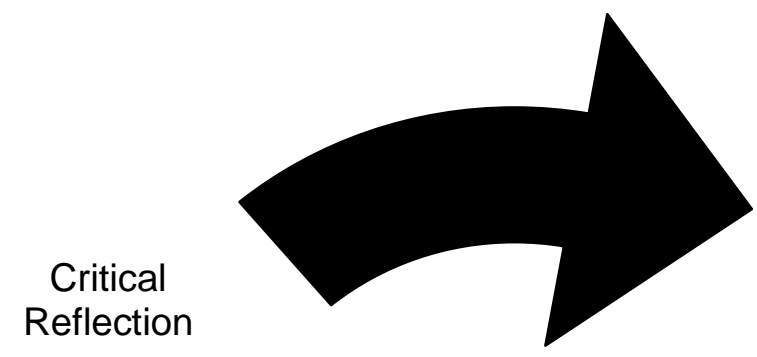

3. Analysis of baseline information \& research findings
6. Reflection on success of implementation
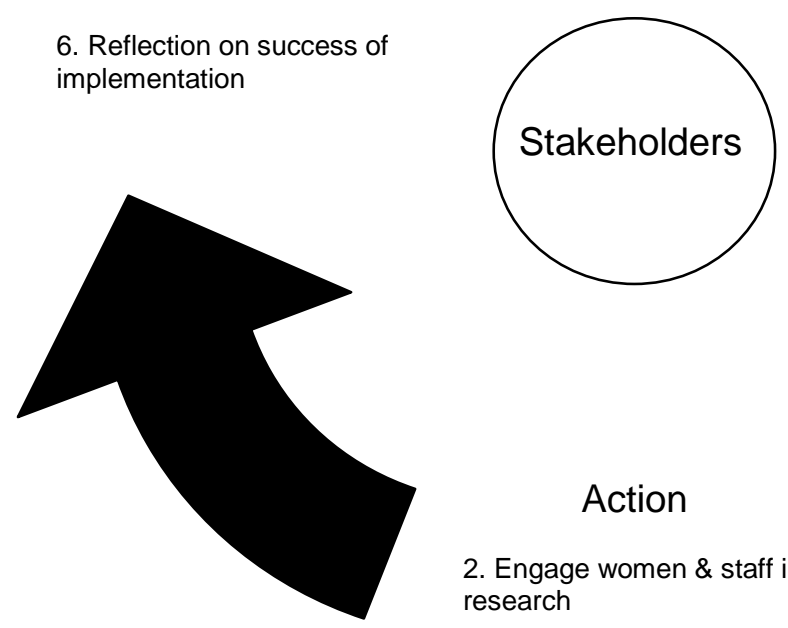

\section{Action}

2. Engage women \& staff in research

\section{Planning}

1. Ethical approval \& collection of baseline data.

4. Implementation plan for change

\section{Implementation of agreed initiatives}

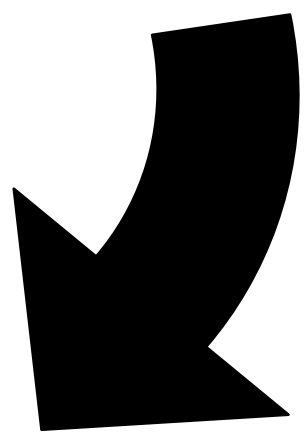

